\title{
Evaluating the Performance of Global Emerging Markets Equity Exchange-Traded Funds
}

\author{
David Blitz and Joop Huij
}

\begin{abstract}
We examine the performance of passively managed exchange-traded funds (ETFs) that provide exposure to global emerging markets equities. We find that the tracking errors of these funds are substantially higher than previously reported levels for developed markets ETFs. ETFs that use statistical index replication techniques turn out to be especially prone to high tracking errors, and particularly so during periods of high cross-sectional dispersion in stock returns. At the same time, we find no convincing evidence that these funds earn higher returns than ETFs that rely on full-replication techniques.
\end{abstract}

Blitz (corresponding author) is the Head of Quantitative Equity Research at Robeco, Coolsingel 120, 3011 AG, Rotterdam, The Netherlands, phone +31 (0)10-2242079, e-mail d.c.blitz@robeco.nl. Huij is Senior Researcher at Robeco and Associate Professor of Finance at the Erasmus University Rotterdam School of Management, Burg. Oudlaan 50, 3000 DR, Rotterdam, The Netherlands, phone +31 (0)10-4081276, e-mail jhuij@rsm.nl. 


\title{
Evaluating the Performance of Global Emerging Markets Equity Exchange-Traded Funds
}

\begin{abstract}
We examine the performance of passively managed exchange-traded funds (ETFs) that provide exposure to global emerging markets equities. We find that the tracking errors of these funds are substantially higher than previously reported levels for developed markets ETFs. ETFs that use statistical index replication techniques turn out to be especially prone to high tracking errors, and particularly so during periods of high cross-sectional dispersion in stock returns. At the same time, we find no convincing evidence that these funds earn higher returns than ETFs that rely on full-replication techniques.
\end{abstract}




\section{Introduction}

A large number of studies have investigated the performance of actively managed equity mutual funds. The main conclusions of these studies are that the average active fund underperforms the market portfolio by the magnitude of its expenses, and that only a relatively small number of active funds show persistent outperformance (see, e.g., Hendricks, Patel and Zeckhauser, 1993; Elton, Gruber and Blake, 1996; Carhart, 1997; and Bollen and Busse, 2005). These findings have had significant implications for developments in the investment management industry. Perhaps most importantly, it has contributed to the increasing popularity of investing in passively managed funds, which aim to replicate broad market indexes at minimal costs. Because passive funds typically have lower costs than active funds, one might expect passive funds to outperform active funds on average. This proposition seems to appeal to a large group of investors.

Exchange-traded funds (henceforth, ETFs) are passive investment vehicles which have become increasingly popular in a relatively short period of time. An important difference with conventional index funds is that, similar to individual stocks, ETFs can be bought and sold throughout the trading day. For more detailed information on the origin and characteristics of ETFs we refer to Haslem (2003). Over the past two decades the number of ETFs has grown from zero to over 2,000 funds, with aggregate assets under management in excess of $\$ 1,000$ billion (Blackrock, 2010). Studies that have examined the performance of ETFs that track U.S. equity indexes conclude that ETF performance is 
predictable to a high degree of accuracy: ETFs generally manage to stay close to their benchmark indexes with low levels of tracking error, and there seems to be a one-to-one negative relation between fund returns and their expenses (see, e.g., Elton, Gruber and Busse, 2004; Poterba and Shoven, 2002; Gastineau, 2004; and Agapova, 2011). The latter result is extended by Blitz, Huij and Swinkels (2011), who show that passive equity funds which invest outside their country of incorporation suffer from an additional drag on performance from missed dividend income, as a result of withholding taxes imposed by foreign tax authorities. For their sample of passive funds listed in Europe they find that the explanatory power of dividend withholding taxes as a determinant of underperformance is at least on par with fund expenses. Svetina and Wahal (2008) also investigate the performance of ETFs that track international equity indexes and find that the tracking error levels of these funds are more than double those of ETFs that track domestic U.S. equity indexes.

The focus of the existing literature is on the performance of ETFs designed to mimic indexes for the U.S. or other developed equity markets. To the best of our knowledge, no study has specifically investigated the performance of ETFs that aim to mimic global emerging markets (GEM) equity indexes. ${ }^{1}$ Global emerging markets comprise countries such as South Korea, China, India, Brazil, South Africa and Russia, which have become increasingly important to investors due to their fast growing economies. This trend is also reflected in the

\footnotetext{
${ }^{1}$ The literature on the performance of actively managed emerging market equity funds is also scarce. Studies that investiagted this subject include Abel and Fletcher (2004), Gottesman and Morey (2007), Huij and Post (2011), and Hayat and Kraeussl (2011).
} 
composition of the MSCI All Countries index, in which the weight of emerging markets has grown from roughly 1 percent in 1988 to around 14 percent today. Klapper, Sulla and Vittas (2004) also document an explosive growth of emerging market funds since the 1990s. Not surprisingly, GEM ETFs have become increasingly popular as a result of these developments. A comprehensive analysis of the performance of GEM ETFs is relevant because it is unclear if results found in the academic literature for U.S. and European equity ETFs carry over directly to GEM ETFs.

The first objective of this paper is to evaluate the overall performance of GEM ETFs. A priori, there are good reasons to expect that it is more complicated to closely track benchmark indexes in emerging than developed markets. An example of a complicating factor with which GEM ETFs need to cope is that many of the underlying markets are geographically located in time zones which are different from the ones in which the ETFs trade. For example, many Asian markets are closed during NYSE opening hours. Johnson (2009) examines the tracking performance of U.S.-listed ETFs on individual foreign countries and finds significantly higher tracking errors when the opening hours of the foreign markets do not overlap with the stock exchanges on which the ETFs are traded. Another complicating factor is foreign exchange-rate volatility. Shin and Soydemir (2010) find that a higher exchange-rate volatility is generally accompanied by a higher tracking error for U.S.-listed ETFs on individual foreign countries.

Moreover, even without the complications arising from time zone differences and exchange-rate volatility, we argue that tracking errors of GEM 
ETFs are likely to be higher than for their developed market counterparts. The reason is that, as we will show in this paper, the cross-sectional dispersion in stock returns is structurally larger in emerging markets than in developed markets. As a consequence, similar-sized deviations between portfolio and index weights typically result in larger return deviations for a GEM ETF than for a developed markets ETF.

Another issue that arises with emerging markets is that stocks in these markets are less liquid and have higher trading costs than stocks in developed markets. For example, Domowitz, Glen and Madhavan (2001) estimate that transaction costs for stocks in emerging markets are twice as high as transaction costs for U.S. stocks, and argue that this is even more than one would expect based on the smaller average market capitalization and higher average volatility of stocks in emerging markets. Bekaert, Harvey and Lumsdaine (2002) and Chiyachantana, Jain, Jiang and Wood (2004) also report significant price pressure effects in emerging markets.

The second objective of this paper is to investigate the implications of the higher trading costs and lower liquidity of emerging markets stocks on the techniques that ETFs have at their disposal to track their benchmark indexes. Generally speaking, passive funds apply two techniques to track their benchmark indexes: full replication, where a fund holds all stocks in the index (or uses derivatives such as swaps to mirror the index), and statistical replication, where a fund intentionally holds only a subset of the index constituents. The latter approach typically involves the use of a statistical optimizer to construct a 
portfolio that is based on a trade-off between estimates of trading costs and ex ante tracking-errors. For a comprehensive overview and technical details of statistical replication tracking techniques we refer to Beasley, Meade and Chang (2003), Beasley and Canakgoz (2009) and Coriellia and Marcellino (2006).

Because investors in emerging markets are confronted with lower liquidity, tracking portfolios that are constructed using statistical replication techniques may incur lower trading costs than portfolios that are constructed using full replication techniques. ${ }^{2}$ At the same time, however, excluding stocks may cause high levels of tracking error in emerging markets because of the larger crosssectional dispersion in stock returns. It is currently unclear how both tracking techniques fare in emerging markets. This study intends to fill this gap in the literature.

Our results indicate that GEM ETFs exhibit substantially higher levels of tracking error than their developed markets counterparts. In fact, we find that half of the GEM ETFs in our sample have such high levels of tracking error that it is arguable if these funds should actually be classified as passive funds. We also find that funds that use statistical replication techniques to track their benchmark indexes are particularly prone to high tracking errors during periods of high crosssectional dispersion in stock returns. At the same time, we do not find convincing evidence that these funds earn higher returns than ETFs that rely on fullreplication techniques to track their benchmark indexes. Similar to developed

\footnotetext{
${ }^{2}$ Frino, Gallagher and Oetomo (2006) argue that liquidity is an even more important issue for passively managed index funds than for actively managed funds, since these funds typically have a high demand for trading immediacy.
} 
markets ETFs, the average underperformance of GEM ETFs comes close to the level one would expect based on expenses and dividend taxation.

\section{Data}

BlackRock (2010) provides a comprehensive overview of ETFs available to investors in various markets. The two main markets for ETFs are the U.S. and Europe, which together account for around 90 percent of global ETF market capitalization. Our sample consists of all ETFs listed in these markets that track a conventional broad emerging markets index and have a live track-record of at least one year. ${ }^{3}$ An overview of the funds in our sample is given in Table 1. The table shows that the aggregate assets under management of the funds in our sample amount to $\$ 67$ billion. Two funds, the iShare (U.S. listing) and the Vanguard fund, account for the vast majority (over 85 percent) of these assets.

\section{[INSERT TABLE 1 ABOUT HERE]}

We use Thomson Financial Datastream to gather the time series of monthly U.S. dollar total returns from inception through December 2010 for each ETF in our sample. These returns are based on closing prices at which the funds were actually traded. In addition, we collected return series based on net asset value (NAV) histories from the websites of the asset managers that provide this

\footnotetext{
${ }^{3}$ Based on the one year data requirement we exclude the MSCI Emerging Markets Source ETF (launched in April 2010), the Schwab Emerging Markets Equity ETF (launched in January 2010) and the GlobalShares FTSE Emerging Markets Fund (launched in December 2009 but closed within a year in October 2010) from the long list of GEM ETFs in Blackrock (2010).
} 
information, specifically iShares (both listings) and Vanguard. ${ }^{4}$ The oldest fund in the sample is the iShare (U.S. listing), with data starting in April 2003, while the youngest fund in the sample is DB x-trackers, with data starting in July 2007. Table 1 also shows that roughly half of the funds in our sample use fullreplication techniques to track their indexes, while the other half uses statistical replication techniques. For full replication we can make a further distinction between funds that buy all the stocks in an index (for example, the Vanguard ETF) and funds that use swaps to obtain full exposure in a synthetic manner (for example, DB x-trackers and Lyxor ETF).

\section{Results}

This section presents our empirical results. We begin with examining GEM ETF tracking-error levels, first over the full history of the funds, and next conditional on whether cross-sectional return dispersion in emerging equity markets is high or low. This is followed by an evaluation of GEM ETF performance.

\subsection{GEM ETF tracking-error levels}

In our first empirical analysis we investigate how close the GEM ETFs in our sample manage to stay to their benchmark indexes. We measure this ability by means of the tracking errors of the funds against their benchmark indexes, i.e., the time-series standard deviation of the return differences between the funds

\footnotetext{
${ }^{4}$ NAV-based total return series are not available through Thomson Financial Datastream, and, unfortunately, not all asset managers provide this information on their websites.
} 
and their benchmark indexes. ${ }^{5}$ Because bid-ask effects, stale prices and time zone differences can give rise to temporary return deviations in the short run, tracking errors based on short-term data may overestimate the tracking error experienced by investors over longer holding periods. In addition to tracking errors based on monthly data we therefore also calculate tracking errors based on (overlapping) quarterly and annual returns. As short-term noise factors do not affect the NAV of a fund, we additionally show tracking error levels computed using NAV returns for the funds that report this information. The results of this analysis are shown in Table 2.

\section{[INSERT TABLE 2 ABOUT HERE]}

Table 2 shows that, in the short run, the ETFs in our sample exhibit high levels of tracking error, in the range of 3 to 6 percent on an annual basis. As expected, tracking errors are lower when estimated using quarterly and annual data, or when based on NAV data. We also observe that, for longer estimation horizons, tracking errors based on closing prices converge to the level of tracking errors estimated using the funds' NAVs, with only small differences remaining at an annual horizon. This finding indicates that a large portion of the high short-run tracking error levels can be attributed to temporary price fluctuations of the ETFs around their NAVs. Nonetheless, the tracking error levels we document for GEM ETFs remain substantially higher than the levels reported for passive funds investing in developed equity markets. For example, Blitz, Huij and Swinkels

\footnotetext{
${ }^{5}$ In these and the following analyses we use benchmark returns which assume full reinvestment of dividends, unless explicitly stated otherwise.
} 
(2011) report annual tracking errors of 0.5 to 0.8 percent for passive funds tracking broad equity indexes for developed markets.

When we consider the funds' tracking error levels and the replication techniques they use, it appears that funds relying on statistical replication exhibit higher levels of tracking error than those that rely on full replication. For example, the iShares (U.S. listing), Credit Suisse and SPDR funds exhibit long-term tracking errors of more than three percent on an annual basis. A vivid example of the possible implications of such high tracking-error levels can be found in the track record of the iShares ETF (U.S. listing), which fell short of its benchmark index by more than 10 percent over the year $2009 .{ }^{6}$ Although funds that exhibit such high tracking-error levels may claim and intend to provide passive exposure, it is arguable if they truly qualify as such.

With long-term tracking errors ranging from 1 to 1.5 percent, the Vanguard, DB x-trackers and Lyxor funds that rely on full replication techniques appear to do a better job at tracking their benchmark indexes than the other ETFs in our sample. Nevertheless, their tracking-error levels remain substantially higher than the figures reported for developed equity markets ETFs. This indicates that staying close to the benchmark index is more challenging for GEM ETFs than for passive funds that invest in developed equity markets.

The remaining fund, the iShares ETF (Ireland listing), is an interesting case, as it is the only statistical-replication fund which manages to achieve a tracking error level close to that of full-replication funds. This is particularly

\footnotetext{
${ }^{6}$ This figure is 7 percent based on NAV data.
} 
striking in light of the fact that the iShares ETF (U.S. listing), which is managed by the same firm and applies the same investment philosophy, exhibits a considerably higher tracking-error level. We contacted Blackrock, which manages the iShares funds, and their explanation for this observation is that although the investment philosophy of the two funds is indeed similar, the funds are managed by independent portfolio management teams, which can make different choices with regard to trading in local shares versus ADRs/GDRs, target levels of transaction cost and spreads and, as is already evident from the data in Table 2, the total number of stocks in portfolio. This example illustrates that although our results indicate that the statistical replication technique is typically accompanied by higher levels of tracking error than the full replication technique, they should certainly not be construed to imply that every fund which uses statistical replication will be unsuccessful at staying close to its benchmark index, nor that every fund which uses full replication is guaranteed to be successful at staying close to its benchmark index.

\subsection{Cross-sectional dispersion in stock returns and tracking error levels}

We now turn to investigating the relation between GEM ETF tracking error levels and cross-sectional dispersion in stock returns in emerging markets. In particular, we investigate if the tracking-error levels of GEM ETFs are higher when crosssectional return dispersion increases, and if this effect is stronger for funds that rely on statistical replication techniques to track their benchmark indexes. To 
motivate this analysis, note that the return difference between a fund and its benchmark index in period $t$ can be expressed as

$$
r_{\text {diff }, t}=\sum_{i}\left(p_{i, t}-b_{i, t}\right)\left(r_{i, t}-r_{b, t}\right)
$$

where $p_{i, t}$ is the portfolio weight in stock $i$ at the beginning of period $t, b_{i, t}$ is the benchmark index weight in stock $i$ at the beginning of period $t, r_{i, t}$ is the return of stock $i$ over period $t$ and $r_{b, t}$ is the return of the benchmark index over period $t$. Equation (1) implies that both the magnitude of stock weight differences and the cross-sectional dispersion in stock returns are factors that can contribute to tracking error. In the extreme case that fund weights are identical to benchmark index weights (perfect full replication), or in the extreme case that the crosssectional dispersion in stock returns is zero (i.e., if all stocks have exactly the same return), the tracking error would be zero.

For our empirical analysis we first compute the dispersion in crosssectional stock returns for the U.S., the European, the Pacific, and emerging equity markets. Our stock return data cover all constituents of the FTSE U.S., FTSE Europe, FTSE Japan-Pacific, MSCl Emerging Markets and S\&P/IFC Emerging Markets indexes over the period January 2003 to December $2010 .^{7}$ For each month in our sample we compute the market capitalization-weighted cross-sectional standard deviation of stock returns in each region. Figure 1 shows the 12-month rolling average return dispersions over time. We clearly

\footnotetext{
${ }^{7}$ Except for the MSCI Emerging Markets index, for which constituent data is only available from January 2004 onwards.
} 
observe that the return dispersion in emerging markets is structurally higher than in the U.S., Europe and the Japan-Pacific regions. For the MSCl Emerging Markets universe, average cross-sectional volatility is around $29 \%$ higher than in the developed market regions, while for the S\&P/IFC Emerging Markets universe, which contains more small stocks, the average cross-sectional volatility is even around $42 \%$ higher. Our finding of large return dispersion in emerging markets is consistent with the findings of Harvey (1995) and Phylaktis and Xia (2006) that, compared to developed markets, additional common factors are required to explain equity returns in emerging markets, and the result of Dey (2005) that the sources of risk in emerging and developed markets are different.

\section{[INSERT FIGURE 1 ABOUT HERE]}

We continue our analysis by splitting our sample into two subsamples, corresponding to a low- and a high-return dispersion regime. The regime classification is based on whether the average cross-sectional dispersion of stock returns in emerging markets over a particular period is below or above its median level over the entire sample period. ${ }^{8}$ For each fund in our sample we then compute tracking error levels conditional on the prevailing dispersion regime. The results using monthly as well as (overlapping) quarterly or annual return data are presented in Table 3.

\section{[INSERT TABLE 3 ABOUT HERE]}

\footnotetext{
${ }^{8}$ For this analysis we use dispersion estimates based on S\&P/IFC index constituent data, as the available history for $\mathrm{MSCl}$ is incomplete. However, Figure 1 indicates that over the overlapping period $\mathrm{MSCl}$ data implies a very similar regime classification.
} 
For all GEM ETFs we observe that tracking error levels are higher during periods of high cross-sectional return dispersion than during periods of low dispersion, regardless of the frequency used to calculate returns. Focusing on the results based on annual return data, which are least affected by short-term noise factors, we observe that the spread in tracking-error levels during low and high return dispersion regimes is particularly large for GEM ETFs that rely on statistical replication. Specifically, we observe tracking error spreads of 1.7 to 3.4 percent for the iShares (U.S. listing), Credit Suisse and SPDR ETFs, which all use statistical replication, versus spreads of only 0.4 to 0.8 percent for the Vanguard, DB $x$-trackers and Lyxor ETFs that rely on full replication techniques. These results indicate that it is more difficult to control long-term tracking error when cross-sectional return dispersion increases, but particularly so for funds relying on statistical replication techniques. ${ }^{9}$

\subsection{GEM ETF performance}

We proceed by evaluating the average performance of GEM ETFs. In Table 4 we first show fund returns minus gross benchmark returns. Gross benchmark returns are calculated assuming full reinvestment of dividends. In the second column of the table we show fund returns minus net benchmark returns. Net benchmark returns are computed assuming the reinvestment of dividends that remain after

\footnotetext{
${ }^{9}$ The exception to this rule is again the iShares (Ireland listing), which we previously observed to be the only statistical-replication fund with a tracking error comparable to the full-replication funds. Not surprisingly, therefore, the observed tracking error spread for this fund is also comparable to that of the full-replication funds.
} 
taxation against the maximum rates applicable to non-resident institutional investors. In the third column of the table we show fund returns minus net benchmark returns plus the expense ratio of a fund. By adding back the expense ratio we adjust for the costs incurred by a fund. Fund total expense ratios are shown in the fourth column of the table.

\section{[INSERT TABLE 4 ABOUT HERE]}

Based on Table 4 we conclude that the average GEM ETF in our sample underperforms its gross benchmark index by 85 basis points per annum. Interestingly, the magnitude of this underperformance is not much different from the figure reported by Blitz, Huij and Swinkels (2011) for a sample of passive funds that mainly invest in developed equity markets. ${ }^{10}$ Another result of that study is that the expected return on an ETF is equal to its gross benchmark index return, minus its expense ratio and minus dividend taxes. This approximation also appears to be a good estimate for the expected return of GEM ETFs, as Table 4 shows that GEM ETF performance adjusted for expenses is very close to net benchmark index returns. Expenses contribute 62 basis points to GEM ETF underperformance, while the estimated impact of dividend taxation is 29 basis points. This amounts to 91 basis points in total, which is very close to the actual underperformance of 85 basis points. The relative impact of dividend withholding taxes and expenses on fund performance in emerging markets differs from that in developed equity markets though. Whereas Blitz, Huij and Swinkels (2011) report that the explanatory power of dividend withholding taxes as a determinant of ETF

\footnotetext{
${ }^{10}$ The authors report that the funds in their sample underperform their benchmark indexes with 50 to 150 basis points per annum, with a median of 84 basis points.
} 
underperformance is at least on par with fund expenses, the impact of withholding taxes appears to be about half that of fund expenses in emerging markets. This finding can be attributed to the fact that dividend withholding taxes are generally lower for emerging than for developed markets, while fund expense ratios tend to be higher. ${ }^{11}$

Our finding that expenses and dividend withholding taxes suffice for explaining the average return of GEM ETFs indicates that other potential explanatory factors, such as trading costs, do not have a material impact on longterm expected fund performance. Although trading costs are known to be higher in emerging markets than in developed markets (Domowitz, Glen and Madhavan, 2001; Chiyachantana, Jain, Jiang and Wood, 2004), GEM ETFs do not appear to perform worse than developed markets passive funds. A possible explanation for this observation might be that the higher trading costs in emerging markets are offset by higher revenues from securities lending activities.

Another interesting observation is that ETFs that rely on statistical replication techniques do not appear to perform better than their full-replication counterparts. To formally test the impact of different replication techniques on GEM ETF performance we perform two pooled regressions. In the first regression we regress benchmark-relative returns of the GEM ETFs on a dummy variable that indicates if an ETF employs full replication techniques or not, and in the second regression we regress squared benchmark-relative returns of the

\footnotetext{
${ }^{11}$ For example, Blitz, Huij and Swinkels (2011) report expense ratios of 35-50 basis points per annum and a dividend withholding tax impact of 50-60 basis points per annum for Europeanlisted ETFs tracking the S\&P 500, MSCI U.S.A., MSCI Europe or MSCI World index.
} 
GEM ETFs on the full-replication dummy and our measure of average crosssectional return dispersion in emerging markets stocks over the same period. We run separate regressions using monthly as well as (overlapping) quarterly or annual return data. The resulting coefficient estimates and adjusted R-squared values are reported in Table 5.

\section{[INSERT TABLE 5 ABOUT HERE]}

The coefficient estimates of the regressions where we use squared ETF benchmark-relative returns as the dependent variable corroborate our previous findings, indicating that GEM ETF tracking-error levels are positively related to cross-sectional return dispersion of emerging market stocks and lower for funds that employ full replication techniques. All $t$-statistics are highly significant. The coefficient estimates of the regression where we use ETF benchmark-relative returns as dependent variable are also consistent with our previous finding that there is no strong evidence in support of the notion that ETFs that employ statistical replication techniques might earn better returns than ETFs that rely on full replication. While we do observe negative point estimates for the full replication dummy variable, all coefficient estimates are statistically insignificant.

\section{Conclusion}

In this paper we examine the performance of exchange-traded funds (ETFs) that provide passive exposure to global emerging markets (GEM) equities. We find that GEM ETFs exhibit higher levels of tracking error than developed markets ETFs, which we relate to the cross-sectional dispersion in stock returns being 
structurally larger in emerging markets. We find that this feature of emerging markets also has important implications for the replication techniques that are used by the ETFs to track their benchmark indexes. We find that especially ETFs that rely on statistical replication are prone to high levels of tracking error, and particularly so during periods of high return dispersion. At the same time there is no convincing evidence that these funds earn better returns than ETFs that rely on full-replication techniques. The long-term average underperformance of GEM ETFs is similar to that of developed markets ETFs. We find that, on average, GEM ETFs fall short of their benchmark indexes by around 85 basis points per annum, which is in line with the expected drag on return due to fund expense ratios plus the impact of withholding taxes on dividends. While ETFs that use statistical replication earn somewhat better returns than ETFs that use full replication, the return differences are only marginal and statistically insignificant. 


\section{References}

Abel, E., and Fletcher, J. (2004), "An Empirical Examination of UK Emerging Market Unit Trust Performance", Emerging Markets Review, Vol. 5, No. 4, pp. $389-408$

Agapova, A. (2011), "Conventional Mutual Index Funds versus Exchange-Traded Funds", Journal of Financial Markets, Vol. 14, No. 2, pp. 323-343

Beasley, J.E., and Canakgoz, N.A. (2009), "Mixed-Integer Programming Approaches for Index Tracking and Enhanced Indexation", European Journal of Operational Research, Vol. 196, No. 1, pp. 384-399

Beasley, J.E., Meade, N., and Chang, T.J. (2003), "An Evolutionary Heuristic for the Index Tracking Problem", European Journal of Operational Research, Vol. 148 , No. 3, pp. 621-643

Bekaert, G., Harvey, C.R., and Lumsdaine, R.L. (2002). "The Dynamics of Emerging Market Equity Flows", Journal of International Money and Finance, Vol. 21, No. 3, pp. 295-350

Blitz, D.C., Huij, J., and Swinkels, L.A.P. (2011), "On the Performance of European Index Funds and ETFs", SSRN working paper, No. 1438484 (forthcoming European Financial Management)

BlackRock (2010), ETF Landscape Global Handbook, Q2 2010

Bollen, N. P. B., and Busse, J. A. (2005), "Short-term Persistence in Mutual Fund Performance", Review of Financial Studies, Vol. 18, No.2, pp. 569-597

Carhart, M.M. (1997), "On Persistence in Mutual Fund Performance", Journal of Finance, Vol. 52, No. 1, pp. 57-82 
Chiyachantana, C.N., Jain, P. K., Jiang, C., and Wood, R.A. (2004), "International

Evidence on Institutional Trading Behavior and Price Impact", Journal of

Finance, Vol. 59, No. 2, pp. 869-898

Coriellia, F., and Marcellino, M. (2006), "Factor Based Index Tracking", Journal of

Banking and Finance, Vol. 30, No. 8, pp. 2215-2233

Dey, K.D. (2005), "Turnover and Return in Global Stock Markets" Emerging Markets Review, Vol. 6, No. 1, pp. 45-67

Domowitz, I., Glen, J., and Madhavan, A. (2001), "Liquidity, Volatility and Equity Trading Costs Across Countries and Over Time", International Finance, Vol. 4, No. 2, pp. 221-255

Elton, E. J., Gruber, M. J., and Blake, C. R. (1996), "The Persistence of RiskAdjusted Mutual Fund Performance", Journal of Business, Vol. 69, No. 2, pp. $133-157$

Elton, E. J., Gruber, M. J., and Busse, J. A. (2004), "Are Investors Rational? Choices among Index Funds", Journal of Finance, Vol. 59, No. 1, pp. 261288

Frino, A., Gallagher, D.R., and Oetomo, T.N. (2006), "Further Analysis of the Liquidity and Information Components of Institutional Orders: Active versus Passive Funds", Pacific-Basin Finance Journal, Vol. 14, No. 5, pp. 439-452 Gastineau, G.L. (2004), "The Benchmark Index ETF Performance Problem", Journal of Portfolio Management, Vol. 30, No. 2, pp. 96-103

Gottesman, A., and Morey, M.R. (2007), "Predicting Emerging Market Mutual Fund Performance", Journal of Investing, Vol. 16, No. 3, pp. 111-122 
Haslem, J.A. (2003), "Mutual Funds: Risk and Performance Analysis for Decision Making", Oxford: Blackwell Publishing

Harvey, C. (1995), "Predictable Risk and Returns in Emerging Markets", Review of Financial Studies, Vol. 8, No. 3, pp. 773-816

Hayat, R.. and Kraeussl, R. (2011), "Risk and Return Characteristics of Islamic Equity Funds" Emerging Markets Review, Vol. 12, No. 2, pp. 189-203

Hendricks, D., Patel, J., and Zeckhauser, R. (1993), "Hot Hands in Mutual Funds: Short-run Persistence of Relative Performance", Journal of Finance, Vol. 48, No. 1 , pp. $93-130$

Huij, J., and Post, T. (2011), "On the Performance of Emerging Markets Equity Mutual Funds", Emerging Markets Review, Vol. 12, No. 3, pp. 238-249 Johnson, W.F. (2009), "Tracking Errors of Exchange Traded Funds", Journal of Asset Management, Vol. 10, No. 4, pp. 253-262

Klapper, L., Sulla, V., and Vittas, D. (2004), "The Development of Mutual Funds Around the World", Emerging Markets Review, Vol. 5, No.1, pp. 1-38

Poterba, J.M, and Shoven, J.B. (2002), "Exchange-Traded Funds: A New Investment Option for Taxable Investors", American Economic Review, Vol. 92, No. 2, pp. $422-427$

Phylaktis, K., and Xia, L. (2006). "Sources of Firms' Industry and Country Effects in Emerging Markets". Journal of International Money and Finance, Vol. 25, No. 3, pp. $459-475$ 
Shin, S., and Soydemir, G. (2010), "Exchange-Traded Funds, Persistence in Tracking Errors and Information Dissemination", Journal of Multinational Financial Management, Vol. 20, No. 4-5, pp. 214-234

Svetina, M., and Wahal, S. (2008), "Exchange Traded Funds: Performance and Competition", SSRN working paper, No.1303643 


\section{Table 1: Sample overview}

This table provides an overview of our sample of exchange-traded funds that provide passive exposure to global emerging markets equities. Starting from the long-list of ETFs provided by BlackRock (2010) we select all U.S. and European listed funds that track a conventional broad emerging markets index and have a live track-record of at least one year. For each fund we show the country of domicile, the target (benchmark) index, the assets under management and the start date of data availability. Source: BlackRock (2010).

\begin{tabular}{llllrrr}
\hline ISIN & Name & Domicile & Index & AuM $\mathbf{( \$ ~ m i n )}$ & $\begin{array}{r}\text { Replication } \\
\text { technique }\end{array}$ & Data start \\
\hline US4642872349 & iShares (U.S. listing) & United States & MSCIEM & 33,628 & statistical & Apr-03 \\
US9220428588 & Vanguard & United States & MSCIEM & 24,313 & full (stocks) & Mar-05 \\
IE00B0M63177 & iShares (Ireland listing) & Ireland & MSCIEM & 3,587 & statistical & Dec-05 \\
LU0292107645 & DB x-trackers & Luxembourg & MSCIEM & 3,565 & full (swaps) & Jul-07 \\
FR0010429068 & Lyxor & France & MSCIEM & 1,275 & full (swaps) & Jun-07 \\
LU02540974466 & Credit Suisse & Luxembourg & MSCIEM & 602 & statistical & Jul-06 \\
US78463X5095 & SPDR & United States & S\&P EM BMI & 140 & statistical & Mar-07 \\
\hline
\end{tabular}




\section{Table 2: Tracking errors}

This table shows tracking errors of the GEM ETFs in our sample. We define tracking error as the time-series standard deviation of the return differences between a fund and its benchmark index. For each fund we calculate tracking errors using data until the end of December 2010 and starting from the first month of data availability, as reported in Table 1. Returns are based on monthly closing prices provided by Thomson Financial Datastream. For some funds we additionally report tracking errors based on net asset value (NAV) data taken from company websites (results reported between parentheses). We show annualized tracking errors based on monthly returns as well as (overlapping) quarterly or annual returns. In addition we show the number of securities in each fund portfolio and it benchmark index, as reported by BlackRock (2010).

\begin{tabular}{|c|c|c|c|c|c|}
\hline \multirow[b]{3}{*}{ Name } & \multicolumn{3}{|c|}{ Annualized tracking error } & \multirow{2}{*}{\multicolumn{2}{|c|}{$\begin{array}{l}\text { Number of } \\
\text { securities }\end{array}$}} \\
\hline & monthlv & auarterlv & annual & & \\
\hline & returns & returns & returns & ETF & Index \\
\hline iShares (U.S. listing) & $6.1 \% \quad(3.2 \%)$ & $4.0 \% \quad(2.8 \%)$ & $3.2 \%(2.9 \%)$ & 382 & 767 \\
\hline Vanguard & $4.8 \% \quad$ (n.a.) & $2.4 \%(1.7 \%)$ & $1.5 \%(1.1 \%)$ & 778 & 767 \\
\hline iShares (Ireland listing) & $3.4 \% \quad(1.4 \%)$ & $2.7 \% \quad(1.3 \%)$ & $1.7 \% \quad(1.4 \%)$ & 329 & 767 \\
\hline DB x-trackers & $5.1 \%$ & $3.1 \%$ & $1.4 \%$ & swap & 767 \\
\hline Lyxor & $3.5 \%$ & $2.4 \%$ & $1.5 \%$ & swap & 767 \\
\hline Credit Suisse & $6.1 \%$ & $4.6 \%$ & $4.4 \%$ & 153 & 767 \\
\hline SPDR & $5.8 \%$ & $4.2 \%$ & $3.6 \%$ & 600 & 1525 \\
\hline
\end{tabular}




\section{Table 3: Tracking errors across low- and high-dispersion regimes}

This table shows tracking errors for our sample of GEM ETFs in low- versus high-dispersion regimes. The return difference between a fund and its benchmark over a certain period is assigned to either the low- or high-dispersion regime based on whether the average cross-sectional stock return dispersion in emerging markets during that period is below or above its median level over our sample period. A tracking error per regime is then calculated by taking the standard deviation of the return differences falling in that regime. We show results based on monthly as well as (overlapping) quarterly or annual return data. The column labeled 'Spread' shows the differences between the tracking errors in the high- and low-dispersion regimes. Cross-sectional return dispersion in a given month is calculated as the market capitalization-weighted cross-sectional standard deviation of the returns of all stocks in the S\&P/IFC Emerging Markets index over that month. For each fund we use data from the first month of data availability, as reported in Table 1, until the end of December 2010. Fund returns are based on monthly closing prices provided by Thomson Financial Datastream.

\begin{tabular}{|c|c|c|c|c|c|c|c|c|c|}
\hline & \multicolumn{3}{|c|}{ monthly data } & \multicolumn{3}{|c|}{ quarterly data } & \multicolumn{3}{|c|}{ annual data } \\
\hline & \multicolumn{3}{|c|}{ dispersion } & \multicolumn{3}{|c|}{ dispersion } & \multicolumn{3}{|c|}{ dispersion } \\
\hline & low & high & spread & low & high & spread & low & high & spread \\
\hline iShares (U.S. listing) & $5.0 \%$ & $7.0 \%$ & $2.0 \%$ & $2.8 \%$ & $4.8 \%$ & $2.0 \%$ & $2.2 \%$ & $3.9 \%$ & $1.7 \%$ \\
\hline Vanguard & $3.6 \%$ & $5.8 \%$ & $2.2 \%$ & $1.8 \%$ & $3.0 \%$ & $1.3 \%$ & $1.2 \%$ & $1.6 \%$ & $0.4 \%$ \\
\hline iShares (Ireland listing) & $3.0 \%$ & $3.7 \%$ & $0.7 \%$ & $1.9 \%$ & $3.2 \%$ & $1.3 \%$ & $1.1 \%$ & $1.7 \%$ & $0.6 \%$ \\
\hline DB x-trackers & $3.0 \%$ & $6.2 \%$ & $3.2 \%$ & $1.5 \%$ & $3.7 \%$ & $2.2 \%$ & $1.0 \%$ & $1.6 \%$ & $0.5 \%$ \\
\hline Lyxor & $2.3 \%$ & $4.1 \%$ & $1.8 \%$ & $1.4 \%$ & $2.7 \%$ & $1.3 \%$ & $0.8 \%$ & $1.6 \%$ & $0.8 \%$ \\
\hline Credit Suisse & $3.4 \%$ & $7.6 \%$ & $4.2 \%$ & $2.0 \%$ & $6.0 \%$ & $4.0 \%$ & $1.6 \%$ & $5.0 \%$ & $3.4 \%$ \\
\hline SPDR & $5.0 \%$ & $6.4 \%$ & $1.3 \%$ & $1.9 \%$ & $5.1 \%$ & $3.2 \%$ & $1.3 \%$ & $3.8 \%$ & $2.5 \%$ \\
\hline
\end{tabular}




\section{Table 4: Performance}

This table shows benchmark-relative performances of the GEM ETFs in our sample. For each fund we consider data until the end of December 2010 and starting from the first month of data availability, as reported in Table 1. Returns are based on monthly closing prices provided by Thomson Financial Datastream. The table shows annual fund returns minus gross benchmark returns, fund returns minus net benchmark returns and fund returns after adding back fund expense ratios minus net benchmark returns. Gross benchmark returns are calculated assuming full reinvestment of dividends, while net benchmark returns are computed assuming the reinvestment of dividends that remain after taxation against the maximum rates applicable to non-resident institutional investors. In the final column we show the total expense ratio (TER) of each fund, as reported by BlackRock (2010).

\begin{tabular}{|c|c|c|c|c|}
\hline \multirow[b]{2}{*}{ Name } & \multicolumn{3}{|c|}{ Annualized benchmark-relative performance } & \multirow{2}{*}{$\begin{array}{l}\text { total } \\
\text { expense } \\
\text { ratio } \\
\text { (TER) }\end{array}$} \\
\hline & $\begin{array}{l}\text { after expenses } \\
\text { gross index }\end{array}$ & $\begin{array}{l}\text { after expenses } \\
\text { net index }\end{array}$ & $\begin{array}{l}\text { before expenses } \\
\text { net index }\end{array}$ & \\
\hline iShares (U.S. listing) & $-0.67 \%$ & $-0.36 \%$ & $0.36 \%$ & $0.72 \%$ \\
\hline Vanguard & $-0.81 \%$ & $-0.51 \%$ & $-0.24 \%$ & $0.27 \%$ \\
\hline iShares (Ireland listing) & $0.02 \%$ & $0.31 \%$ & $1.07 \%$ & $0.75 \%$ \\
\hline DB x-trackers & $-1.07 \%$ & $-0.80 \%$ & $-0.15 \%$ & $0.65 \%$ \\
\hline Lyxor & $-1.95 \%$ & $-1.67 \%$ & $-1.03 \%$ & $0.65 \%$ \\
\hline Credit Suisse & $-1.37 \%$ & $-1.09 \%$ & $-0.40 \%$ & $0.70 \%$ \\
\hline SPDR & $-0.08 \%$ & $0.18 \%$ & $0.78 \%$ & $0.59 \%$ \\
\hline average & $-0.85 \%$ & $-0.56 \%$ & $0.06 \%$ & $0.62 \%$ \\
\hline median & $-0.81 \%$ & $-0.51 \%$ & $-0.15 \%$ & $0.65 \%$ \\
\hline
\end{tabular}




\section{Table 5: Regression results}

This table shows results of two pooled regressions. In Panel A we regress benchmark-relative returns of the GEM ETFs on a dummy variable that indicates if an ETF employs full replication techniques or not, and in Panel B we regress squared benchmark-relative returns of the GEM ETFs on the full-replication dummy and our measure of average crosssectional return dispersion in emerging markets stocks over the same period. Cross-sectional return dispersion in a given month is calculated as the market capitalization-weighted cross-sectional standard deviation of the returns of all stocks in the S\&P/IFC Emerging Markets index over that month. We show results based on monthly as well as (overlapping) quarterly or annual returns. For each fund we use data from its inception until the end of December 2010. Fund returns are based on closing prices provided by Thomson Financial Datastream.

\begin{tabular}{lcccccc}
\hline & monthly data & quarterly data & \multicolumn{2}{c}{ annual data } \\
\hline Panel A: dependent variable: returns & & & & & \\
Intercept & -0.03 & $(-0.36)$ & -0.15 & $(-1.37)$ & -0.68 & $(-3.52)$ \\
b(FullRepl) & -0.06 & $(-0.38)$ & -0.12 & $(-0.67)$ & -0.35 & $(-1.11)$ \\
adj. R-sq. & \multicolumn{2}{c}{$0 \%$} & \multicolumn{2}{c}{$0 \%$} & & $0 \%$ \\
\hline Panel B: dependent variable: squared returns & & & & & \\
Intercept & -0.20 & $(-0.26)$ & -3.85 & $(-2.81)$ & -3.30 & $(-0.84)$ \\
b(FullRepl) & 0.27 & $(3.73)$ & 0.77 & $(5.80)$ & 1.43 & $(3.82)$ \\
b(Dispersion) & -0.82 & $(-2.11)$ & -2.23 & $(-3.54)$ & -8.45 & $(-5.66)$ \\
adj. R-sq. & $4 \%$ & $10 \%$ & & $12 \%$ \\
\hline
\end{tabular}




\section{Figure 1: Cross-sectional stock return dispersion across different equity markets}

This figure shows cross-sectional stock return dispersion across different equity markets over time. Our stock return data cover all constituents of the FTSE U.S., FTSE Europe, FTSE Japan-Pacific, MSCl Emerging Markets and S\&P/IFC Emerging Markets indexes over the period January 2003 (January 2004 for MSCI Emerging Markets) to December 2010. For each month in our sample we compute the market capitalization-weighted cross-sectional standard deviation of stock returns in each region. The figure shows the 12-month rolling average of the return dispersions calculated in this way.

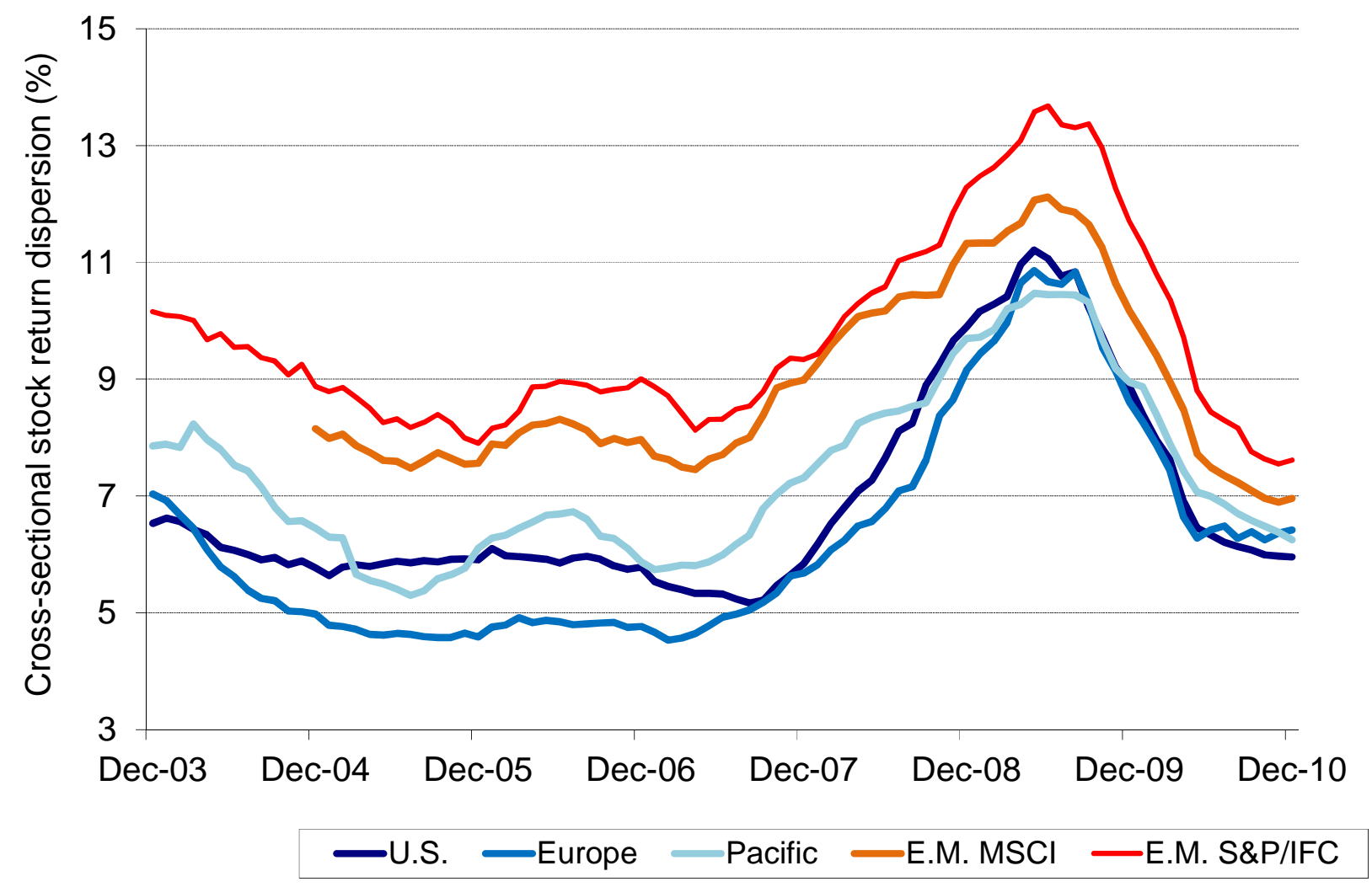

